\title{
Identification of Blood Meal of Sand Flies in a Cutaneous Leishmaniasis Endemic Area, Volta Region-Ghana
}

\author{
Edna Dzifa Doe ${ }^{1,2, ~ *, ~ G o d w i n ~ K w a k y e-N u a k o ~}{ }^{1}$, Alexander Egyir-Yawson ${ }^{1}$ \\ ${ }^{1}$ Department of Biomedical Sciences, University of Cape Coast, Cape Coast, Ghana \\ ${ }^{2}$ Cellular and Clinical Research Centre, Radiological and Medical Sciences Research Institute, Accra, Ghana
}

\section{Email address:}

dzidey@yahoo.com (E. D. Doe), Gkwakye-nuako@ucc.edu.gh (G. Kwakye-Nuako),

alexander.egyir-yawson@ucc.edu.gh (A. Egyir-Yawson)

${ }^{*}$ Corresponding author

\section{To cite this article:}

Edna Dzifa Doe, Godwin Kwakye-Nuako, Alexander Egyir-Yawson. Identification of Blood Meal of Sand flies in a Cutaneous Leishmaniasis Endemic Area, Volta Region-Ghana. American Journal of Biomedical and Life Sciences. Vol. 8, No. 4, 2020, pp. 69-75.

doi: $10.11648 /$ j.ajbls.20200804.12

Received: May 28, 2020; Accepted: June 10, 2020; Published: June 20, 2020

\begin{abstract}
Background: Vector incrimination is of utmost importance in the transmission of Leishmania species identified in the Volta region of Ghana. The feeding preference of sand flies provides valuable information about the vector-host interactions, including reservoir host. Objective: The main aim of this study was to identify the blood meal in collected sand flies and its source from three villages in a cutaneous leishmaniasis endemic area in the Ho Municipality. Method: Sand flies was collected using CDC light straps and sticky paper traps from Lume Atsiame, Dodome Dogblome and Dodome Awuiasu. They were morphologically identified by taxonomic keys. DNA was extracted from the individual sand flies using the potassium acetate extraction method. Polymerase chain reaction (PCR) amplification of cytochrome b gene (cyt $b)$ fragment was carried out and subsequently DNA sequenced. Results: Of a total of three hundred and sixty-three (363) female sand flies that were analysed, eighty-four (84) representing 23.14\% were positive for blood meal presence with an amplified DNA of the expected size, $359 \mathrm{bp}$. Out of the number that was sequenced, the cyt $b$ sequencing revealed that four (4) blood fed females fed on bloodmeal from human (Homo sapiens) and house mouse (Mus musculus). Conclusion: The blood meal presence was more predominant in Sergentomyia ghesquierei and least in Sergentomyia schwetzi. This may aid in the development of effective strategies to control cutaneous leishmaniasis in the endemic areas.
\end{abstract}

Keywords: Cytochrome B Gene, Feeding Preferences, Identification, Polymerase Chain Reaction, Sequencing

\section{Introduction}

Leishmaniasis, caused by the protozoan parasite Leishmania is transmitted by the bite of various species of sand flies. These sand flies are blood sucking insects of great medical importance. They require blood to supplement the essential proteins for development and production of their eggs during their gonotrophic cycle [1, 2]. The disease is caused by several species of intracellular parasites of the genus Leishmania, which presents three distinct clinical manifestations: cutaneous (CL), mucocutaneous (MCL) and visceral forms (VL) [30]. CL is the most common and self-healing and VL is the most severe.

Some species of the sand fly have preference for particular or group of animal host species, while most others tend to be generalists due to availability of hosts [1]. Research into the source of blood meal of sand flies which feed on a wide range of mammalian hosts, including birds, dogs, domestic livestock, man and rodents is of great eco - epidemiological significance [3-5]. This is because they enable the correct identification of the vector feeding preferences [6] and contribute to the explanation of the natural transmission cycle in a given area [7]. It is worth noting that sand flies are known to have a low and weak flight pattern $[8,9]$ and as such will not travel too far to get their source of blood meal. Thus, one of the most important steps towards predicting and controlling this disease is by monitoring the sand flies in a region [10].

The identification of the source of blood meal of blood sucking insects were until recently conducted using mainly 
serological techniques such as the enzyme-linked immune-sorbent assays, latex agglutination test and the precipitin test [3]. These techniques are now regarded to be time-consuming and with low level of sensitivity [11]. Currently, DNA based molecular techniques [12, 13] have thus gained popularity because they are sensitive and specific although the approach is laborious and quite expensive. Valinsky et al., [14] reported that targets used for identifying the source of blood meal to the species level include polymerase chain reaction (PCR) and sequencing of the mitochondrial genes; cytochrome $\mathrm{b}(c y t b)$, cytochrome $\mathrm{c}$ oxidase 1 (COI), rRNA genes (12S, 16S, and 18S), and nuclear genes. These techniques are based on DNA sequence analysis of targets previously amplified by PCR [15]. These techniques have further been used for the molecular monitoring of leishmaniasis as well as for determining the feeding behaviour of sand flies [16]. As an alternative to DNA techniques, two approaches utilizing liquid chromatography-mass spectrometry (LC-MS/MS) and MALDI-TOF MS protein profiling have been designed [17] to identify blood meals.

In Ghana, Kweku et al., [18] reported in their study that the geographic range of leishmaniasis is limited by the sand fly vector and its feeding preferences. There is thus, limited research carried out on the blood meal source of sand flies in the cutaneous leishmaniasis focus in the Ho Municipality of the Volta Region, Ghana. Thus, in this study, PCR amplification of the mitochondrial cytochrome $\mathrm{b}(c y t b)$ gene was carried out followed by direct DNA sequencing to detect presence of blood meal and its source for the sand flies collected in the CL endemic area.

\section{Materials and Methods}

\subsection{Study Area}

The Ho town doubles as the capital of the Municipality and the Regional Capital of the Volta Region (Figure 1).

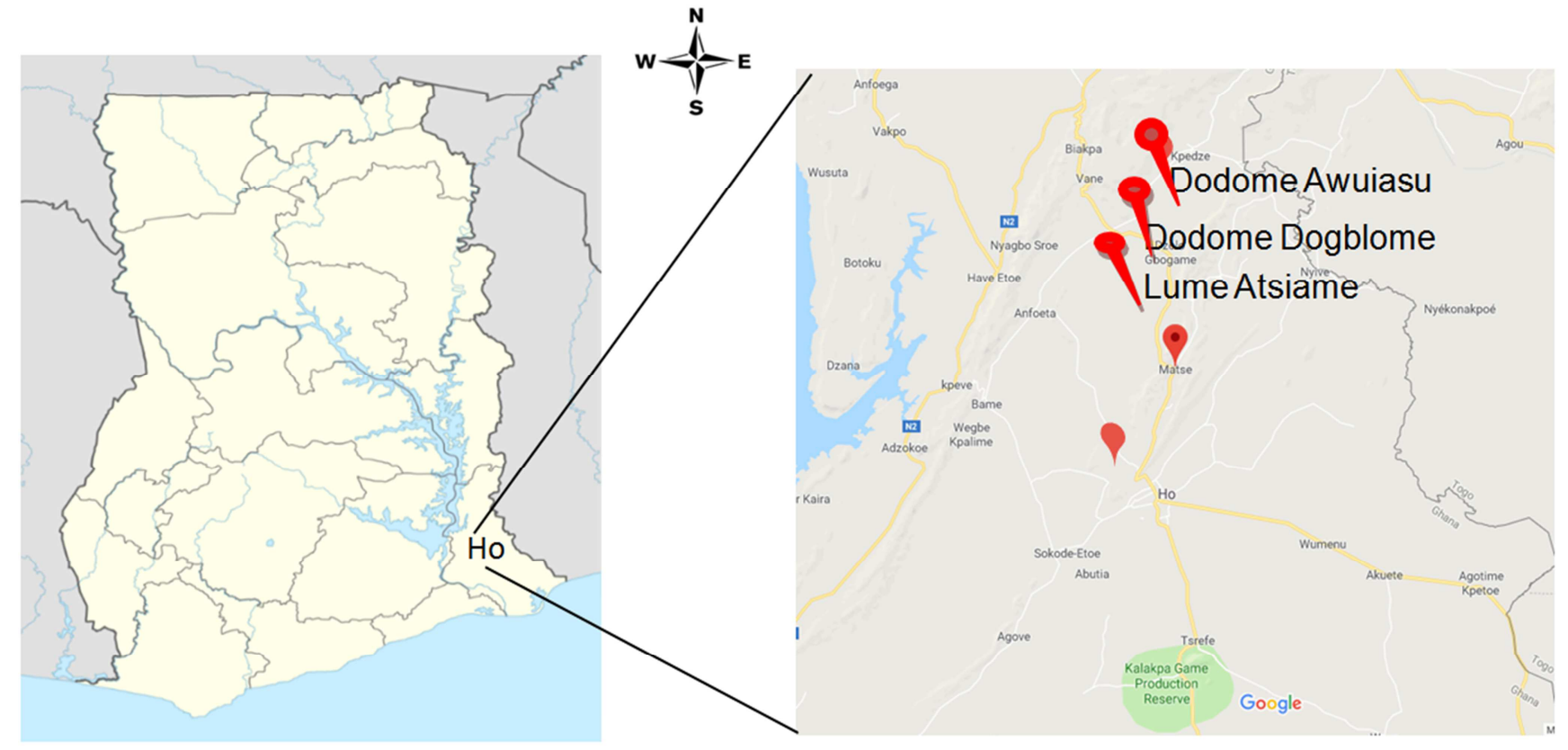

Figure 1. Map of Ghana showing the study areas.

It lies between latitudes $6^{\circ} 36^{\prime} 43^{\prime \prime} \mathrm{N}$ and longitude $0^{\circ} 28^{\prime} 13^{\prime \prime} \mathrm{E}$. The Municipality is a moist semi-deciduous forest zone with villages dotted around. The vegetation of the Municipality is mainly forest and forest savannah. The population of the Municipality according to 2010 population and housing census stands at 177,281 with 83,819 males and 93,462 females as stated by the Ghana Statistical Services Report [19]. The study was carried out in three communities namely Lume Atsiame $\left(6.619918^{\circ} \mathrm{N}, 0.464762^{\circ} \mathrm{E}\right)$, Dodome Dogblome $\left(6.760774^{\circ} \mathrm{N}\right.$, $\left.0.51546^{\circ} \mathrm{E}\right)$ and Dodome Awuiasu $\left(6.767553^{\circ} \mathrm{N}, 0.514789^{\circ} \mathrm{E}\right)$. The major economic activities of the population are agriculture, animal farming and trading.

\subsection{Ethic Issue}

Ethical clearance was obtained from the University of Cape
Coast Institutional Review Board (UCCIRB/CHAS/2017/32). The leaders of the endemic communities and family heads consented to this investigation before setting the traps for the sand flies' collection around the residence.

\subsubsection{Sand Fly Collection}

The collection of sand fly was carried out every day (from $6 \mathrm{pm}$ to 6am) in November and December 2017, January, February, March, April, May, June and August 2018. Siting of the CDC light and sticky traps were randomly selected for sand fly collections in the three endemic areas in the Ho Municipality (Figure 1). The selected communities represent areas in the Municipality where cases of CL had been reported [20].

A total of three (3) CDC light traps and 20 sticky traps were set from dusk to dawn (approximately 12hr) each day for the 
collection of flies. The collected sand flies by the CDC light traps were freeze-killed at $-20^{\circ} \mathrm{C}$ and sorted out into labelled $1.5 \mathrm{ml}$ eppendorf tubes containing silica gel for dry preservation. However, the collected sand flies by the sticky traps were preserved in $70 \%$ ethanol. The tubes were secured in sealed sample collection bags and transported to the entomology laboratory for morphological identification.

\subsubsection{Morphological Identification}

Taxonomical identification of the collected sand flies was carried out on the basis of the morphological criteria [21]. The identification was based on three morphology features - the cibarium, pharynx and spermatheca. Phlebotomus species had a cibarium which laced cibarial teeth and a pigmented patch whilst Sergentomyia species had both the cibarial teeth and pigment patch present.

\subsection{DNA Extraction}

DNA was extracted from each sand fly using the potassium acetate extraction method as described by Aransay et al., [22] with slight modifications. The individual sand fly was grinded with disposable pestle in $1.5 \mathrm{~mL}$ labelled tubes. One hundred and fifty microliters $(150 \mu \mathrm{L})$ of extraction buffer, which was made up of $1 \%$ sodium dodecyl sulphate [SDS], $25 \mathrm{mM} \mathrm{NaCl}$ and $25 \mathrm{mM}$ EDTA was added, and tubes were placed in a water bath at $65^{\circ} \mathrm{C}$ for 30 minutes. Following the addition of $100 \mu \mathrm{L}$ of $3 \mathrm{M}$ potassium acetate ( $\mathrm{pH} 7.2)$, the homogenates were incubated on ice for 30 minutes and then centrifuged for 15 minutes at 13,000 rpm. The supernatant was recovered, and DNA was precipitated by the addition of $600 \mu \mathrm{L}$ of $100 \%$ ethanol. The homogenate was placed in the freezer at 30 minutes for 1 hour, then centrifuged at $13000 \mathrm{rpm}$ for 25 minutes, after which the ethanol was discarded and the resulting pellet air dried for 10 minutes. The DNA pellets was re-suspended in $50 \mu \mathrm{L}$ of $0.5 \mathrm{X}$ Tris-EDTA (TE) (pH 8.0). Five-microliter $(5 \mu \mathrm{L})$ portions of the DNA extracted were used for PCR amplification.

\subsection{Identification of Blood Meal in Sand Flies by PCR}

The identification of the blood meal in the individual sand fly was based on PCR amplification of cytochrome b gene (cyt $b$ ) carried in the mitochondrial DNA (mt DNA) of mammalian hosts. A $359 \mathrm{bp}$ fragment of the $c y t b$ gene was amplified using previously described primers [23]. DNA extracts from individual sand fly were used as template and the primers $c y t b$ forward: 5' - CCA TCC AAC ATC TCA GCA TGA AA-3' and $c y t b$ reverse 5'- GCC CCT CAG AAT GAT ATT TGT CCT CA-3' (Macrogene, Korea) were designed for the amplification of $359 \mathrm{bp}$ of the conserved region of the $c y t b$ gene. The $359 \mathrm{bp}$ cyt $b$ segment was amplified using $0.125 \mu \mathrm{L}$ of One Taq DNA polymerase [1.25 U/50 $\mu \mathrm{L}$ ] (New England Biolabs, Inc.) in a total reaction volume of $25 \mu \mathrm{L}$ consisting of $5 \mu \mathrm{L}$ of buffer (containing $1.8 \mathrm{mM}$ of $\mathrm{MgCl}$ ) [5X], $0.5 \mu \mathrm{L}$ of $10 \mathrm{mM}$ dNTPs (dATP, dCTP, dGTP and dTTP), $0.5 \mu \mathrm{L}$ of each of primer $[10 \mu \mathrm{M}], 5 \mu \mathrm{L}$ of DNA and sterilized water to make up the final volume. The thermal cycling conditions used were: an initial denaturation at $95^{\circ} \mathrm{C}$ for $10 \mathrm{mins}$, amplification was performed with 40 cycles consisting of denaturation at $94^{\circ} \mathrm{C}$ for $30 \mathrm{~s}$, annealing at $52^{\circ} \mathrm{C}$ for $30 \mathrm{~s}$, extension at $68^{\circ} \mathrm{C}$ for $45 \mathrm{~s}$, followed by a final extension at $68^{\circ} \mathrm{C}$ for 5 mins, and $4^{\circ} \mathrm{C}$ as holding temperature. For each PCR, a negative control containing sterilized distilled water separately and a male sand fly separately instead of DNA was included. The positive control was positive blood fed mosquito. The reaction was carried out in the BIO RAD System Peltier Thermal Cycler. The amplified PCR products were subjected to electrophoresis on a $2 \%$ agarose gel in $1 \mathrm{X}$ TAE buffer stained with ethidium bromide $(10 \mathrm{mg} / \mathrm{mL})$ at $80 \mathrm{~V}$ for 1 hour, with a $100 \mathrm{bp} / 200 \mathrm{bp}$ DNA Ladder provided as molecular weight size standard. The final amplicons were visualized under ultraviolet light and subsequently photographed.

\subsection{Sequence and Phylogenetic Analysis}

The PCR amplified products obtained was sequenced by Sanger's method in both forward as well as reverse directions and sequencing results were obtained from Applied Biosystems (ABI): ABI 3500XL Genetic Analyser, POP7 ${ }^{\mathrm{TM}}$ and Brilliant Dye ${ }^{\mathrm{TM}}$ Terminator v3.1 (NimaGen BV, Nijmegen). The same primers used for the PCR reactions was used. The nucleotide sequences from both strands were aligned using the DNASTAR (Lasergene) software. Sequences was then compared with the GenBank database using NCBI (National Centre for Biotechnology information) BLASTN (https://blast.ncbi.nlm.nih.gov/Blast.cgi), aligned and analysed in MEGA (Molecular Evolutionary Genetics Analysis) version 7. Phylogenetic tree was constructed using the Neighbour Joining (NJ) method.

\section{Results}

\subsection{PCR Results}

A total of 727 sand flies was captured during a nine (9) months sampling period from the three study communities. Females made up 76.07\% (553/727) of the sand flies collected whereas males made up 23.93\% (174/727). Males are not involved in the transmission cycle of the parasite since male sand flies are not blood feeders and were thus excluded from the study. Of the 553 female sand flies captured, 363 representing $65.64 \%$ were morphologically identified successfully by observing under an optical microscope. A total of $69.97 \%$ (254/363) were captured at Dodome Dogblome, $23.69 \%(86 / 363)$ at Lume Atsiame and 6.33\% (23/363) at Dodome Awuiasu. It is worth mentioning that only two sand fly species were identified: Phlebotomus (3.31\%) and Sergentomyia (96.69\%). The morphologically identified species are namely Phlebotomus rhodaini, Sergentomyia antennata, Sergentomyia africana, Sergentomyia buxtoni, Sergentomyia collarti, Sergentomyia dureini, Sergentomyia ghesquierei, Sergentomyia hamoni, Sergentomyia ingrami, Sergentomyia schwetzi and Sergentomyia similima. Sergentomyia africana was the most abundant species $(\mathrm{n}=95$; $26.17 \%)$ and Sergentomyia collarti was the least identified $(\mathrm{n}=1 ; 0.28 \%)$. 
The female sand flies were grouped as non-engorged and engorged. The non-engorged totalled $65.56 \%$ (238/363) while the engorged totalled $34.43 \%$ (125/363). Majority of the engorged sand flies were collected at Dodome Dogblome. After amplification of the cytochrome $b$ gene by PCR on all the morphologically identified female sand flies, $67.2 \%$ $(84 / 125)$ of the engorged female sand flies showed presence of blood meal by having the DNA product of $359 \mathrm{bp}$. The remaining $32.8 \%(41 / 125)$ were negative despite the presence of blood in their abdomen. The species of sand fly that showed

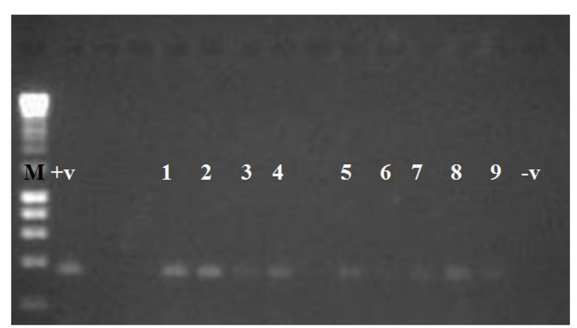

the presence of blood meal (Figures 2 and 3) included Phlebotomus rodhaini, Sergentomyia ghesquierei, Sergentomyia similima, Sergentomyia africana, Sergentomyia antennata, Sergentomyia ingrami, Sergentomyia hamoni and Sergentomyia schwetzi (Table 1). Since there was no yield in PCR products of negative control, this implied that only host DNA was amplified.

The cytochrome $\mathrm{b}$ gene for blood meal was analysed with AY509658.1, HQ180173.1, LC088152.1 and JX266260 from the GenBank.

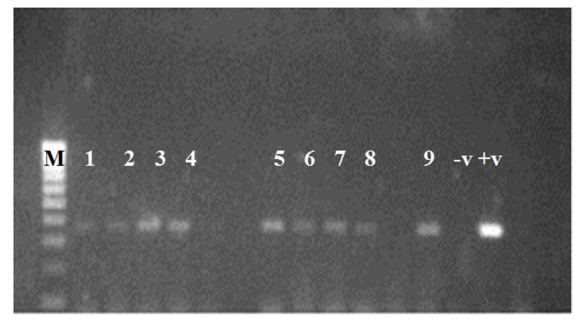

Figure 2. (LEFT) Agarose gel electrophoresis of PCR products of Phlebotomus rodhaini Lane M: Molecular weight marker (200bp) and (RIGHT). Sergentomyia similima Lane M: Molecular weight marker (100bp) after amplification of cyt b gene (359bp). $+v$, positive control $-v$, negative control.
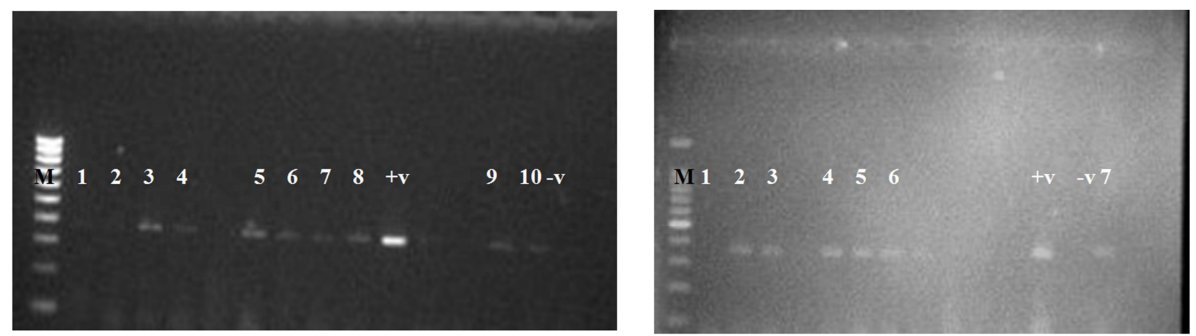

Figure 3. (LEFT) Agarose gel electrophoresis of PCR products of Sergentomyia ghesquierei (RIGHT) Sergentomyia africana after amplification of cyt b gene (359bp). Lane M: Molecular weight marker (100bp). $+v$, positive control of mosquito $-v$, negative control.

\subsection{Sequence Analysis Results}

The samples that showed presence of blood meal having the DNA product of $359 \mathrm{bp}$, was sent for sequencing. Only seven was able to be sequenced representing $8.3 \%$. Unfortunately, of the seven, three did not show good quality sequence data. However, in order to have a fair idea of the source of blood meal of these four resulting sand flies (one Phlebotomus rodhaini and three Sergentomyia similima species) that showed sequencing results, the nucleotide sequence data obtained was edited and then subjected for BLAST with NCBI nucleotide sequence data library. The identity of the source of blood meal for these four species was assessed based on retrieved cyt $b$ sequences, considering the closest database matches at species level of vertebrate hosts.

After multiple alignments of experimentally generated sequences and those obtained from the BLAST and in addition to reference sequences obtained from the GenBank, a Neighbour-Joining phylogenetic tree was constructed using MEGA 7 program (Figure 4). The phylogenetic tree analysis showed that the resulting four species possess sequences in close relation to that of Mus musculus (house mouse) and Homo sapiens (human).

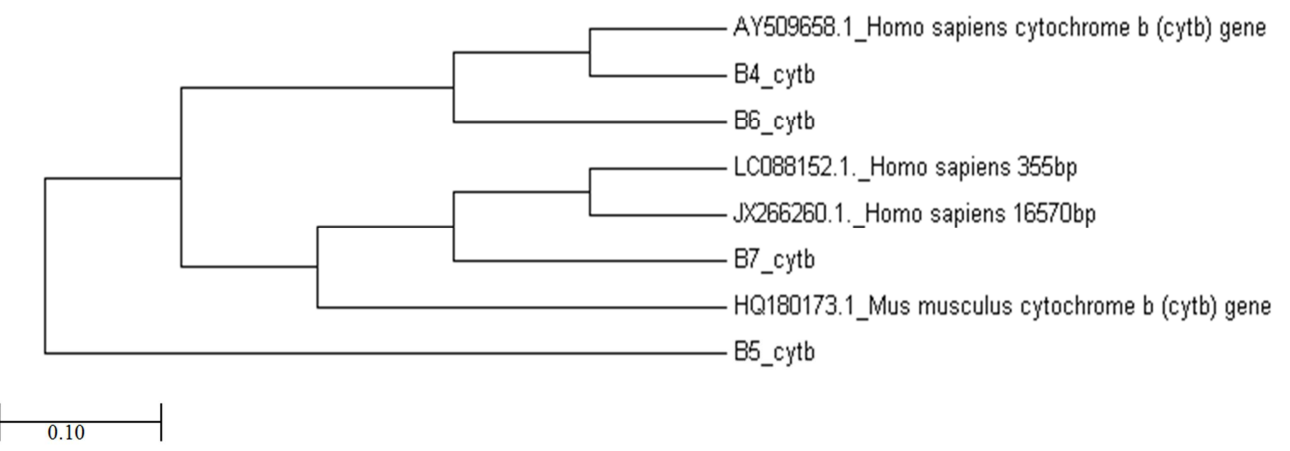

Figure 4. Neighbour joining tree using cyt b gene among four sand fly species. AY509658.1, LCO088152.1, JX266260.1 and HQ180173.1 are the reference sequence. B4 (Phlebotomus rodhaini), B5-B7 (Sergentomyia similima) are the sequences of this studies. 
Table 1. The percentage (\%) of blood meal present in each morphologically identified sand fly species.

\begin{tabular}{lll}
\hline Sand fly species & $\begin{array}{l}\text { No. of sand flies } \\
\text { identified (\%) }\end{array}$ & $\begin{array}{l}\text { Blood meal } \\
\text { identification (\%) }\end{array}$ \\
\hline Sergentomyia africana & $95(26.17)$ & $10(2.75)$ \\
Sergentomyia. similima & $93(25.62)$ & $20(5.51)$ \\
Sergentomyia qhesquerei & $83(22.86)$ & $27(7.44)$ \\
Sergentomyia schwetzi & $32(8.82)$ & $3(0.83)$ \\
Sergentomyia ingrami & $19(5.23)$ & $5(1.38)$ \\
Phlebotomus rodhaini & $12(3.31)$ & $8(2.20)$ \\
Sergentomyia antennata & $11(3.03)$ & $6(1.65)$ \\
Sergentomyia hamoni & $8(2.20)$ & $5(1.38)$ \\
& 363 & $84(23.14)$ \\
\hline
\end{tabular}

\section{Discussion}

The analysis of source of blood meal provides valuable information about the feeding behaviour of each sand fly species and the role of a particular host in Leishmania foci [24]. It also provides which control strategies may be effectively implemented [25]. In the effort to achieving the objective of this study, which was to acquire basic data on the identification of blood meal in sand fly and its source, a molecular approach was used that involved amplification of potential host gene and subsequent sequencing [7]. This choice was based on the higher sensitivity of molecular methods in this endeavour. Hadj-Henni et al., [26], stated in their study that $c y t b$ is a good marker as it increases the accuracy of blood meal identification of female sand flies containing blood in their gut.

Of the morphologically identified number of female sand flies collected, $96.69 \%$ was of the genus Sergentomyia with $3.31 \%$ of the genus Phlebotomus (Table 1). This observation was consistent with studies carried out by Boakye et al., [27], Mosore, [28] and Nzelu et al.,[29] in the endemic area where Sergentomyia species was captured in abundance. Nevertheless, Sergentomyia is believed to transmit lizard Leishmania species whereas Phlebotomus transmit human pathogenic species of Leishmania [30]. However, studies in Ghana and elsewhere have suggested the possible involvement of Sergentomyia minuta, Sergentomyia ingrami, Sergentomyia hamoni and Sergentomyia darlingi as vectors of leishmaniasis [29, 31-33]. This reiterating the fact that some Sergentomyia species disclose periodic or opportunistic anthropophilic feeding behaviour. In this study, of the eleven sand fly species identified morphologically, presence of blood meal was observed in eight of the species (Table 1) with Sergentomyia ghesquierei species recording the most presence of blood meal.

Kent and Norris, [34] reported in their study that blood meal identification through successful molecular analysis depend on the amount of blood ingested and the period of blood digestion in the midgut of the insect. In the current study, although $34.43 \%(125 / 363)$ of the sand flies was blood fed, which was obvious during the morphological identification, however, only eighty-four of such sand flies tested positive by PCR. The fact that PCR could not detect the presence of blood meal in the sand fly could be attributed to the display of inter and intraspecific variation in sand flies' sizes [3]. As a result, the volume of blood they ingest during blood feeding could be low, ranging from 0.1 to $1.0 \mathrm{~L}$, thus escaping detectable threshold by this method $[3,35]$.

In order to zero-in on the particular hosts, in the endemic communities that these sand flies, may have been feeding on among the wide range of potential mammalian hosts, it was important to obtain DNA sequence data. Unfortunately, the quality of most of the DNA sequences of the amplified product were not good enough for further analysis. However, with the four sequences obtained, the BLAST analysis provided a narrow range of potential host. The analysis by the phylogenetic tree (Figure 4) showed close relatedness of the sequences to Mus musculus (house mouse) and Homo sapiens (human). This study using PCR and sequencing have observed that the source of blood meal could probably be from Mus musculus (house mouse) and Homo sapiens (human) though, further studies have to be carried out to ascertain this. Nonetheless, elsewhere in Africa, studies carried out by Bennai et al., [36], Berdjane-Brouk et al., [31], Tateng et al., [37] and Yared et al., [38], reported source of blood meal in Sergentomyia darlingi, Sergentomyia minuta, Sergentomyia similima and Sergentomyia schwetzi respectively to be Homo sapiens thus sending information across that some of these species of sand flies feed on human blood.

The sequences B4, B5, B6 and B7 (Figure 4) are closely related to both house mouse and human. With more improved DNA sequence quality, the relatedness of these sequence will be better understood. It is worth noting that the B4 is blood meal from Phlebotomus rhodaini while B5, B6 and B7 are blood meal from Sergentomyia similima. Despite the wide distribution of Phlebotomus rodhaini in most leishmaniasis endemic foci, it is considered a rare species and therefore it is ignored as a possible vector of leishmaniasis parasites [28]. Nevertheless, Anderson et al., [39] reports in their study that though Phlebotomus rodhaini was collected in small numbers it is a known vector for Leishmania major elsewhere in West Africa specifically Mali.

The findings of this study although may not be fully appreciated for the comprehensive identification of the potential hosts and therefore the basic epidemiological information for vector control programs [3], it set the agenda that, it is a worthy research path to take and that the molecular approach as indicated by Ernieenor Faraliana et al., [40] is the most straightforward and specific method to identify blood meals. Furthermore, this approach is ideal since primers may be improved based on initial data and later employed to amplify conserved homologous DNA fragments from diverse potential of vertebrate blood sources within the locality [41].

\section{Conclusion}

Conclusively, it can be said that sand flies are opportunistic feeders and their host preference is subject to how available and how abundant the blood meal source is. In this study, 
Dodome Dogblome recorded the highest number of sand flies. Sergentomyia africana was the most abundant species identified whilst Sergentomyia collarti was the least identified. The most presence of blood meal was recorded in Sergentomyia ghesquierei and the least in Sergentomyia schwetzi. Phlebotomus rodhaini which is considered as one of the implicating vectors in the endemic area had eight out of twelve of its species showing presence of blood meal after amplification of $c y t b$ gene $(359 \mathrm{bp})$. It can also be said that four (4) blood fed females fed on blood meal from human (Homo sapiens) and house mouse (Mus musculus).

\section{Acknowledgements}

The authors acknowledge the Department of Biomedical Sciences, School of Allied Health Sciences of the University of Cape Coast. The services rendered by Mr. Sylvester Nyarko and Dr. Adolf Kofi Awua is gratefully acknowledged.

\section{Conflicts of Interest}

The authors declare that they have no competing interests.

\section{References}

[1] Azizi, K., Moemenbellah-Fard, M. D., Kalantari, M., and Fakoorziba, M. R. Molecular Detection of Leishmania major kDNA from Wild Rodents in a New Focus of Zoonotic Cutaneous Leishmaniasis in an Oriental Region of Iran. Vector-Borne and Zoonotic Diseases, 2012; 12, 844-850.

[2] Depaquit, J., Grandadam, M., Fouque, F., Andry, P. E., and Peyrefitte, C. Arthropod-borne viruses transmitted by Phlebotomine sandflies in Europe: a review. Euro Surveillance: Bulletin Europeen Sur Les Maladies Transmissibles European Communicable Disease Bulletin, 2010; 15: 19507.

[3] Abbasi, I., Cunio, R., and Warburg, A. Identification of Blood Meals Imbibed by Phlebotomine Sand Flies Using Cytochrome PCR and Reverse Line Blotting. Vector-Borne and Zoonotic Diseases, 2009; 9: 79-86.

[4] Azizi, K., Askari, M. B., Kalantari, M., and Moemenbellah-Fard, M. D. Molecular detection of Leishmania parasites and host blood meal identification in wild sand flies from a new endemic rural region, south of Iran. Pathogens and Global Health, 2016; 110: 303-309.

[5] Fonteles, R. S., Pereira Filho, A. A., Moraes, J. L. P., Pereira, S. R. F., Rodrigues, B. L., and Rebêlo, J. M. M. Detection of Leishmania DNA and Blood Meal Identification in Sand Flies (Diptera: Psychodidae) From Lençois Maranhenses National Park Region, Brazil. Journal of Medical Entomology, 2018; 55; 445-451.

[6] González, E., Jiménez, M., Hernández, S., Martín-Martín, I., and Molina, R. Phlebotomine sand fly survey in the focus of leishmaniasis in Madrid, Spain (2012-2014): seasonal dynamics, Leishmania infantum infection rates and blood meal preferences. Parasites \& Vectors, 2017; 10; 368.

[7] Quaresma, P. F., Carvalho, G. M. de L., Ramos, M. C. das N. F., and Andrade Filho, J. D. (2012). Natural Leishmania sp. reservoirs and phlebotomine sand fly food source identification in Ibitipoca State Park, Minas Gerais, Brazil. Memórias do Instituto Oswaldo Cruz, 2012; 107: 480-485.

[8] Claborn, D. The biology and control of leishmaniasis vectors. Journal of Global Infectious Diseases, 2010; 2; 127.

[9] Roy, D. N., and Brown, A. W. A. The Entomology (Bangalone: The Bangalone Printing and Publishing Co. Ltd.), 1970.

[10] Dokianakis, E., Tsirigotakis, N., Christodoulou, V., Poulakakis, N., and Antoniou, M. Identification of wild-caught phlebotomine sand flies from Crete and Cyprus using DNA barcoding. Parasites \& Vectors, 2018; 11: 94.

[11] Maleki-Ravasan, N., Oshaghi, M., Javadian, E., Rassi, Y., Sadraei, J., and Mohtarami, F. Blood Meal Identification in Field-Captured Sand flies: Comparison of PCR-RFLP and ELISA Assays. Iranian Journal of Arthropod-Borne Diseases, 2009: 3: 8-18.

[12] Garlapati, R. B., Abbasi, I., Warburg, A., Poche, D., and Poche, $\mathrm{R}$. Identification of bloodmeals in wild caught blood fed Phlebotomus argentipes (Diptera: Psychodidae) using cytochrome b PCR and reverse line blotting in Bihar, India. J. Med. Entomol., 2012; 49: 515-521.

[13] Lutomiah, J., Omondi, D., Masiga, D., Mutai, C., Mireji, P. O., Ongus, J., Linthicum, K. J., and Sang, R. Blood meal analysis and virus detection in blood-fed mosquitoes collected during the 2006-2007 rift valley fever outbreak in Kenya. Vector Borne Zoonotic Dis., 2014; 14: 656-664.

[14] Valinsky, L., Ettinger, G., Bar-Gal, G. K., and Orshan, L. Molecular Identification of Bloodmeals From Sand Flies and Mosquitoes Collected in Israel. Journal of Medical Entomology, 2014; 51: 678-685.

[15] Llanes-Acevedo, I. P., Arcones, C., Gálvez, R., Martin, O., Checa, R., Montoya, A., Chicharro, C., Cruz, S., Miró, G., and Cruz, I. (2016). DNA sequence analysis suggests that cytb-nd1 PCR-RFLP may not be applicable to sand fly species identification throughout the Mediterranean region. Parasitology Research, 2016; 115: 1287-1295.

[16] Baum, M., de Castro, E. A., Pinto, M. C., Goulart, T. M., Baura, W., Klisiowicz, D. do R., and Vieira da Costa-Ribeiro, M. C. Molecular detection of the blood meal source of sand flies (Diptera: Psychodidae) in a transmission area of American cutaneous leishmaniasis, Paraná State, Brazil. Acta Tropica, 2015; 143: 8-12.

[17] Dvorak, V., Halada, P., Hlavackova, K., Dokianakis, E., Antoniou, M., and Volf, P. Identification of phlebotomine sand flies (Diptera: Psychodidae) by matrix-assisted laser desorption/ionization time of flight mass spectrometry. Parasites \& Vectors, 2014; 7: 21.

[18] Kweku, M. A., Odoom, S., Puplampu, N., Desewu, K., Nuako, G. K., Gyan, B., Raczniak, G., Kronmann, K. C., Koram, K., Botero, S., Boakye, D., and Akuffo, H. (2011). An outbreak of suspected cutaneous leishmaniasis in Ghana: lessons learnt and preparation for future outbreaks. Global Health Action, 2011; 4: 527.

[19] Ghana Statistical Services. Ghana Statistical Services Report, 2014.

[20] Directorate of Health Services. Directorate of Health Services, Ho, 2013. 
[21] Abonnenc, E. (1972). Sand flies from the Ethiopian region (Diptera, Psychodidae). Paris ORSTOM memoiirs multigr., 1972; 55: 289.

[22] Aransay, A. M., Scoulica, E., and Tselentis, Y. Detection and Identification of Leishmania DNA within Naturally Infected Sand Flies by Seminested PCR on Minicircle Kinetoplastic DNA. Applied and Environmental Microbiology, 2000; 6: 1933-193.

[23] Steuber, S., Abdel-Rady, A., and Clausen, P.-H. PCR-RFLP analysis: a promising technique for host species identification of blood meals from tsetse flies (Diptera: Glossinidae). Parasitology Research, 2005; 97: 247-254.

[24] Alcover, M. M., Gramiccia, M., Di Muccio, T., Ballart, C., Castillejo, S., Picado, A., Portús, M., and Gállego, M. Application of molecular techniques in the study of natural infection of Leishmania infantum vectors and utility of sand fly blood meal digestion for epidemiological surveys of leishmaniasis. Parasitology Research, 2012; 111: 515-523.

[25] González, E., Gállego, M., Molina, R., Abras, A., Alcover, M. M., Ballart, C., Fernández, A., and Jiménez, M. Identification of blood meals in field captured sand flies by a PCR-RFLP approach based on cytochrome b gene. Acta Tropica, 2015; 152: 96-102.

[26] Hadj-Henni, L., De Meulemeester, T., Depaquit, J., No $\tilde{«}$, P., Germain, A., Helder, R., and Augot, D. Comparison of Vertebrate Cytochrome b and Prepronociceptin for Blood Meal Analyses in Culicoides. Frontiers in Veterinary Science, 2015: 2 .

[27] Boakye, Wilson M. D., and Kweeku M (2005). A Review of Leishmaniasis in West Africa. Ghana Medical Journal, 2005; 39: 94-97.

[28] Mosore, M. Leishmania infection in sand flies in a Cutaneous Leishmaniasis focus in Ghana. Master of Phylosophy. Kwame Nkrumah University of Science and Technology. 2015.

[29] Nzelu, C. O., Kato, H., Puplampu, N., Desewu, K., Odoom, S., Wilson, M. D., Sakurai, T., Katakura, K., and Boakye, D. A. First Detection of Leishmania tropica DNA and Trypanosoma Species in Sergentomyia Sand Flies (Diptera: Psychodidae) from an Outbreak Area of Cutaneous Leishmaniasis in Ghana. PLoS Neglected Tropical Diseases, 2014; 8: e2630.

[30] Bates, P. A. Transmission of Leishmania metacyclic promastigotes by phlebotomine sand flies. International Journal for Parasitology, 2007; 37: 1097-1106.

[31] Berdjane-Brouk, Z., Koné, A. K., Djimdé, A. A., Charrel, R. N., Ravel, C., Delaunay, P., del Giudice, P., Diarra, A. Z., Doumbo, S., Goita, S., Thera, M. A., Depaquit, J., Marty, P., Doumbo, O. K., and Izri, A. First Detection of Leishmania major DNA in Sergentomyia (Spelaeomyia) darlingi from Cutaneous Leishmaniasis Foci in Mali. PLoS ONE, 2012; 7: e28266.
[32] Jaouadi, K., Bettaieb, J., Bennour, A., Salem, S., Rjeibi, M. R., Chaabane, S., Yazidi, R., Khabouchi, N., Gharbi, A., and Salah, A. B. (2017). First Report on Natural Infection of Phlebotomus sergenti with Leishmania tropica in a Classical Focus of Leishmania major in Tunisia. The American Journal of Tropical Medicine and Hygiene, 2017; 97: 291-294.

[33] Chargui, N., Slama, D., Haouas, N., Rmadi, L., and Babba, H. Transmission cycle analysis in a Leishmania infantum focus: Infection rates and blood meal origins in sand flies (Diptera: Psychodidae). Journal of Vector Ecology, 2018; 43: 321-327.

[34] Kent, R. J., and Norris, D. E. (2005). Identification of mammalian blood meals in mosquitoes by a multiplexed polymerase chain reaction targeting cytochrome $\mathrm{B}$. The American Journal of Tropical Medicine and Hygiene, 2005; 73: 336-342.

[35] Daba, S., Daba, A., Shehata, M. G., and El Sawaf, B. M. A simple micro-assay method for estimating blood meal size of the sand fly, Phlebotomus langeroni (Diptera: Psychodidae). Journal of the Egyptian Society of Parasitology, 2004; 34: 173182.

[36] Bennai, K., Tahir, D., Lafri, I., Bendjaballah-Laliam, A., Bitam, I., and Parola, P. Molecular detection of Leishmania infantum DNA and host blood meal identification in Phlebotomus in a hypoendemic focus of human leishmaniasis in northern Algeria. PLOS Neglected Tropical Diseases, 2018; 12: e0006513.

[37] Tateng, A. N., Kirstein, O. D., Ngouateu, O. B., Krüger, A., von Stebut, E., Maurer, M., Payne, V. K., Warburg, A., and Dondji, B. First detection of Leishmania donovani in sand flies from Cameroon and its epidemiological implications. Tropical medicine \& international health: TM \& IH, 2018; 23: 1014 1021.

[38] Yared, S., Gebresilassie, A., Abbasi, I., Aklilu, E., Kirstein, O. D., Balkew, M., Brown, A. S., Clouse, R. M., Warburg, A., Hailu, A., and Gebre-Michael, T. A molecular analysis of sand fly blood meals in a visceral leishmaniasis endemic region of northwestern Ethiopia reveals a complex host-vector system. Heliyon, 2019; 5: e02132.

[39] Anderson, J. M., Samake, S., Jaramillo-Gutierrez, G., Sissoko, I., Coulibaly, C. A., Traoré, B., Soucko, C., Guindo, B., Diarra, D., Fay, M. P., Lawyer, P. G., Doumbia, S., Valenzuela, J. G., and Kamhawi, S. Seasonality and Prevalence of Leishmania major Infection in Phlebotomus duboscqi Neveu-Lemaire from Two Neighboring Villages in Central Mali. PLoS Neglected Tropical Diseases, 2011; 5: e1139.

[40] Ernieenor Faraliana, C., Mariana, A., and Tze Ming, H. (2013). PCR Amplification of Mitochondrial Cytochrome B Gene of Animals in Malaysia. The Experiment, 2013; 15: 1064-1071.

[41] Kent, R. J. Molecular methods for arthropod bloodmeal identification and applications to ecological and vector-borne disease studies. Molecular Ecology Resources, 2009; 9: 4-18. 